\title{
De la naturaleza educativa de la educación teatral y de sus rasgos pertinentes
}

\author{
On the educational nature of theatre education and its relevant traits
}

\author{
Manuel F. Vieites \\ Escuela Superior de Arte Dramático de Galicia
}

\begin{abstract}
Resumen
Siempre que en España se acomete una reforma educativa, emergen voces que reclaman una mayor presencia de la educación teatral en la educación general. Este trabajo considera las razones de tal demanda, asentadas en el potencial educativo que la educación teatral, para, a continuación, ofrecer una propuesta de ordenación del campo y saber de las disciplinas más adecuadas a cada etapa educativa, en función de sus finalidades y de las características del sujeto de la educación, buscando las denominaciones más apropiadas. Finalmente, se presenta una propuesta razonada para la normalización de la educación teatral en la enseñanza obligatoria y en el bachillerato.

Palabras clave: educación teatral, currículo, expresión dramática, expresión teatral.
\end{abstract}

\begin{abstract}
Whenever an educational reform is undertaken in Spain, numerous voices claim for a larger presence of theatre education in the stages of pre-university education. This paper considers the reasons for such a claim, settled in the educational potential of theatre education. Then it offers a proposal for the cartography of the field in order to establish which disciplines should be appropriate at each stage, both in terms of aims and objectives and the characteristics of the subject of education, and also considering appropriate names for the disciplines considered. Finally, we present a reasoned proposal for the normalization of theatre education from kindergarten to high school.

Keywords: Theatre in education, curriculum, drama, theatre.
\end{abstract}

\section{Introducción}

En el análisis y justificación del espacio que la educación teatral deba tener en la educación general se hacen necesarios, al menos, cuatro discursos: (1) la reconstrucción histórica de la tradición pedagógica de la pedagogía teatral; (2) el análisis de la dimensión formativa de un conjunto de prácticas educativas que se agrupan bajo el sintagma teatro y educación; (3) la consideración de las disciplinas a que esa dimensión formativa de lo teatral dé lugar en su concreción curricular, y, finalmente, (4) los procesos mediante los que se deban formar los especialistas en educación teatral general. Ofrecemos ahora una aproximación a esos cuatro relatos, prestando especial atención al tercero. En la concepción de la educación teatral general partimos de una propuesta propia (Vieites, 2014a), entendiéndola como un área educativa al servicio de la formación integral de la persona.

Para mostrar la dimensión educativa del teatro, la que justificaría su presencia curricular, no hay nada mejor que analizar la esencia del teatro pues pudiera tener mucho que ver con la esencia misma de la educación. Grotowski señalaba que el teatro puede prescindir de casi todo, menos de la comunión directa y viva entre un actor y un espectador, en tanto Brook formulaba una hermosa metáfora en torno a un espacio vacío por el que transita una persona mientras otra la mira, estableciendo así el principio de la convención en la que se asienta todo acto teatral. En 1936, Dieste, en su glosa a El nacimiento de la tragedia de Nietzsche, titulada "La vieja piel del mundo", imaginaba así el nacimiento del teatro: "En alguna vendimia se cuentan episodios felices de los ausentes y los muertos. El que los cuenta va y viene y se agita y representa. Y hay un instante de júbilo $\mathrm{y}$ de embriaguez en que todos se reconocen con sorpresa, porque se recuerdan" (1995, p. 211).

En las últimas escenas de la película En busca del fuego asistimos a la celebración final que tiene lugar una vez que la mujer de otra tribu, que rescatan y les acompaña en su aventura, muestra cómo crear el fuego; mientras la lumbre ilumina la vida, uno de los tres viajeros toma el cráneo de algún animal y apoyándose en el gesto, en el movimiento, en el sonido, y en unas onomatopeyas que aún no son palabras pero dotadas ya de significado, presenta ante los otros acontecimientos de su aventura lejos del clan: el encuentro con la manada de lo que hoy conocemos como mamut. De pronto, aquel humano se transforma para asumir y mostrar la alteridad. El hecho más singular es el desdoblamiento: el individuo simula ser otro y se convierte en otros: en el narrador, en él mismo recordado, en el animal, en el hombre que maneja un palo y que se enfrenta a la manada. Ese individuo, que ya es actor, representa ante los demás y representa lo que recuerda, o decide seleccionar aquello que considera más sustantivo, o ilustra las imágenes que inundan su mente, con lo que el pasado vuelve al presente, se actualiza, se recrea. Nace el teatro y, al mismo tiempo, nace la historia. Un descubrimiento fascinante. Aquella escena breve y maravillosa, en los últimos instantes de la película de Annaud, muestra algunas características del hecho teatral, que coinciden con las que consideraban Dieste, Grotowski o Brook: el teatro es expresión, es creación y es comunicación de relatos, de historias de vida.

En efecto, el teatro es, ante todo, un acto de comunicación en el que un emisor asume el rol de actor y un receptor asume mantenerse durante la duración del acto en ese rol, aceptando la convención que el primero le propone en relación con la historia que le quiere contar y con el mundo que con tal finalidad ha de crear. Para recrear ese mundo, y para replicar las conductas de las personas que lo habitan, la persona que asume el rol 
de actor genera una acción vinculada a la experiencia, a partir de las herramientas expresivas de que dispone, fundamentalmente la expresión corporal, gestual, cinética, oral, rítmica, musical, plástica o incluso escrita. Pero todas esas formas, modalidades o áreas de expresión confluyen en una que las aglutina: la dramática. Una modalidad de expresión que diferentes teóricos de la comunicación han analizado en momentos diversos y que sería propiamente un modo de conducta que todos desarrollamos en nuestra vida diaria, en tanto con ella jugamos roles. Por eso tantos poetas han utilizado la metáfora dramática al hablar de la conducta, de la vida. "All the world's a stage" dirá Jaques en As You Like It, de William Shakespeare.

La expresión dramática es la base del teatro, porque lo que el receptor, o espectador, contempla no es más que la recreación de un mundo en el que un actor replica, mediante la expresión teatral, la conducta dramática de un personaje, como se puede ver en la figura número 1 .

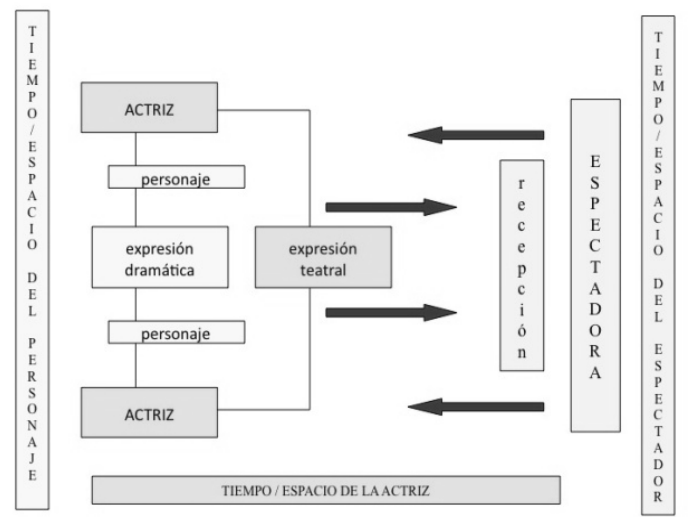

Figura 1. La comunicación dramática. Elaboración propia

El teatro es así un proceso de comunicación con dos planos: la expresión dramática y la expresión teatral. En el primer caso nos situamos en el mundo de lo real (y en el mundo real del personaje), en tanto en el segundo pasamos al mundo del arte. Y la educación, como han señalado diferentes autores (Sarason, 2002), no deja de ser un proceso de comunicación en el que emisores y receptores también construyen y aceptan una convención aunque con finalidades diferentes.

\section{La reconstrucción histórica}

El estudio de la genealogía de una tradición pedagógica propia en educación teatral, y en sus dimensiones científica, empírica o normativa, hasta la propia emergencia de la pedagogía teatral (Vieites, 2013), es una empresa tan fascinante como desatendida, sobre todo en el ámbito de la educación teatral general ubicada en el currículo escolar, pues las prácticas no formales, como el teatro escolar cuentan con un mayor número de estudios (Vieites, 2014b).

En esta reconstrucción por hacer destacan algunas propuestas que se desarrollan en los Estados Unidos de América e Inglaterra entre finales del siglo XIX y los dos primeros decenios del XX y que podemos situar en el origen de lo que más adelante será el desarrollo curricular de la educación teatral general.
Courtney ([1974] 1989) ofrece una de las más interesantes genealogías de lo que entendemos por educación teatral, que hace derivar de cuatro grandes líneas de trabajo: "learning by doing" que vincula con Dewey; "learning through play" con Rousseau; "learning by dramatic doing" con Cook, y "learning through theatre" con una larga tradición de teatro escolar en este país (Cervera, 1982).

Si bien la propuesta de Courtney tiene especial relevancia, olvida una interesante línea de trabajo que cobra fuerza en los Estados Unidos de América a principios del siglo XX vinculada con lo que diferentes autores denominan "dramatic instinct", "dramatic impulse" o "dramatic expression". Así, Merril señala como el "dramatic instinct" se debe entender como "a mode of thinking, of feeling, and of study, as well as a mode of expression" (1914, p. 50). Del instinto dramático, o "tendance dramatique", se ocuparon autores como William James (1890, p. 409) o Curry (1896), propuestas con un enorme eco en Alice M. Herts (1911) o Emma S. Fry (1913) autoras de sendos volúmenes en cuyo título destacan expresiones como "educational theatre" o "educational dramatics". Un impulso, o modo de expresión, pensamiento y acción, estudiado por Elkonin en lo que el psicólogo ruso denomina "juego protagonizado" (1980, pp. 41-68).

Aunque el estudio del desarrollo de lo que ha sido la educación teatral general genera enorme interés en tanto informa de cómo se han conformado movimientos tan importantes como los denominados "drama in education" y "theatre in education" (Bolton, 1984; Siks, 1985), para los objetivos de nuestro estudio tiene especial relevancia el concepto de "instinto teatral", también explorado por el director ruso Evreinoff en lo que definía como "our acting instinct" (1927, p. 13), en tanto se pueda vincular con lo que cabría definir como "conducta dramática", si la comunicación se puede entender como una acción dramática (Burke, 1945), a la que la persona accede a través del juego (Winnicott, [1971] 1982), creando un "espacio transicional", o "marco" para la experiencia (Goffman, 1974)

Como han puesto de manifiesto autores diversos (Huizinga, [1954] 1972; Caillois, 1967) el juego es fundamental en la formación de la persona, y el juego dramático especialmente relevante en la construcción y reconstrucción de la realidad, y de ahí deriva su dimensión educativa, especialmente relevante en tanto configura una forma específica de aprendizaje asentada en la acción, la exploración, el descubrimiento y el uso del método hipotético-deductivo en tanto todo juego parte de un hacer como si, y por ello, desde los inicios del siglo $\mathrm{XX}$, el método dramático se utiliza para enseñar y aprender en muy diferentes áreas (FinlayJohnson, 1911; Cook, 1917).

\section{La razón educativa}

Bowater señalaba hace años que uno de los problemas que más negativamente afectan al desarrollo de la educación teatral es el hecho de que una parte importante del profesorado ha renunciado a pensar en los fundamentos de su praxis, sin trasladar a la opinión 
pública la dimensión formativa del teatro (1985, p. 209). Ciertamente, no se ha sabido explicitar la dimensión educativa del teatro a partir del marco de experiencia que propone. Y mostrar esa "razón educativa" es uno de los retos fundamentales del presente, empresa común a la que queremos contribuir con este trabajo. En nuestra opinión cabe analizar esa dimensión formativa considerando que el teatro:

- Es expresión y comunicación. La expresión dramática es una de las modalidades de expresión del individuo, a partir de la acción, del rol, del uso del lenguajes y códigos como el gestual, el cinético, el corporal..., en la que se asienta la expresión teatral como forma artística. Ésta es un instrumento para transmitir relatos que configuran la experiencia de la persona pero también la cosmogonía del grupo, lo que supone una forma de establecer normas y pautas de conducta, y pasa a ser un recurso para educar. Desde siempre el teatro ha sido un medio privilegiado para la transmisión de ideas. Se cuenta que en Babilonia y en Abydos los sacerdotes transmitían a las masas los mitos de la creación a través de grandes representaciones rituales, en las que también establecían los roles que deberían cumplir como miembros de la misma.

- Es un medio de conocimiento que nos sitúa frente al otro y frente a la historia. Esa dimensión cognoscitiva se deja sentir en Grecia, donde textos y espectáculos exploraban temas que preocupaban a la República: el libre albedrío con Edipo, las relaciones entre tradición y Estado en Antígona, la responsabilidad del ciudadano en Filoctetes o la grandeza de Atenas y los efectos de la guerra en Los persas. Se representa al otro para conocerlo, para entenderlo, para explicarlo, para interpretarlo, y con él a nosotros mismos, porque el otro es nuestro reflejo y nuestro espejo.

- Es diversión. La experiencia genera conocimiento pero también es fuente de diversión. Llegamos así a la catarsis (liberación) y a la anagnórisis (reconocimiento de un nuevo estado de cosas), efectos de la tragedia sobre los que escribirá Aristóteles en su Poética.

- Es encuentro y prefigura una esfera pública pues se crea un marco de expresión y comunicación, un espacio colectivo, en el que otros individuos irán mostrando, con el paso de los siglos y otras formas creativas, sus ideas y propuestas.

Por otro lado, en la generación de la expresión teatral desde la expresión dramática, o en el propio desarrollo de ésta, situamos la otra vertiente del factor educativo del teatro. Imaginemos un grupo de niños y niñas realizando un juego tan sencillo como "La cajita". Cuando el profesor lo indica todas y todos se convierten en cajitas sorpresa y cuando alguien abre la cajita, de ella salen... mariposas que vuelan, y que viven una determinada peripecia; luego se cierra la cajita, se vuelve a la posición inicial, acurrucados, y se vuele e abrir, y salen personas sin techo que buscan comida en un contenedor y todo el grupo cuenta una historia que pasa de unas o otros... En todo momento adecuamos nuestra acción, la expresión y nuestra conducta a aquello que la cajita, al abrirse, nos propone, y que el grupo genera mediante un proceso de creación colectiva, en tanto la historia se construye entre todos. En algún momento ese trabajo de grupo se puede presentar ante otros grupos de clase, o ante madres y padres, y así la expresión dramática deviene en expresión teatral, con el rol de actor y de actriz. El juego es mucho más que un juego, pues permite reconstruir la experiencia y construir un mundo dramático, para lo que se hace necesario realizar determinadas tareas que dan cuenta de los aprendizajes realizados. Hablar de "hacer teatro" implica entonces referir:

- La creación de un marco de experiencia (Goffman, 1974) de carácter ficticio y lúdico, de un "espacio transicional" siguiendo a Winnicott, asentado en la capacidad de la persona para jugar (Caillois, 1967), para jugar a ser otro, en lo que se ha definido como "juego protagonizado" (Elkonin, 1980), sea en función de las necesidades de la existencia, sea en un proceso de expresión extra-cotidiano y en ocasiones de naturaleza artística (Schechner, 2002).

- La creación, en ese marco, de relatos de vida, de experiencia, en los que encontramos personas en situaciones, en conflictos, en acciones y en lugares y tiempos que corren en paralelo a lo real.

- El uso del rol, vinculado con la generación de la acción (Luckmann, 1996), la situación, el conflicto y los universos de ficción (Dolezel, 1999), que tienen un anclaje en lo real y lo reproducen, lo que implica una replica, o reconstrucción, de procesos vida (Watzlawick, Bavelas y Jackson, 1991).

- La exploración, desarrollo, y uso específico, y en bastantes ocasiones muy especializado, de los recursos expresivos de la persona, especialmente en lo que atañe a la expresión oral, la corporal o la gestual (Barker, 1977), y en todo lo que tiene que ver con el uso del espacio y el tiempo, con fines expresivos y comunicativos, como señalaron Hall o Birdwhistell (Winkin et el., 1984).

- La fuerza experimental de una acción asentada en el principio del "hacer como si", que brota de la capacidad de jugar (Huizinga, 1972), pues, como decía Brook en 1968, "una obra de teatro es juego" (2012, p. 189). Nace de una premisa básica del pensamiento hipotético-deductivo: ¿Qué pasaría si...? (Passatore et al., 1984).

- Un uso específico de la situación dramática, que se crea a partir de unas circunstancias dadas lo que implica desarrollar lo que hemos definido como "dramaturgia de la situación", adecuación de la conducta a las exigencias de cada nueva situación en función del estándar que determinen los horizontes de expectativas (Giner, 2010), y utilizando la improvisación como estrategia de adaptación (Hodgson y Richards, 1982).

- Un proceso de relación permanente con la alteridad, con el otro y con lo otro, que en todo caso implica una mirada al yo, y siempre en un contexto de ficción, generado por el mágico "como si”. 
- Un proceso permanente de interacción grupal, que demanda habilidades y competencias en relación, expresión y comunicación, sea con los que forman parte del grupo, con los que conforman el universo de ficción, o con los que integran el público.

Podríamos decir entonces que la dimensión educativa de la educación teatral deriva, entre otras cosas, de un proceso de trabajo:

- asentado en la acción a través de procedimientos como juego, juego dramático, juego de roles, dramatización, improvisación, creación colectiva,

- centrado en la exploración de la realidad y la ficción, en la construcción y reconstrucción de la experiencia, en la ideación dinámica de mundos dramáticos,

- orientado al desarrollo del potencial expresivo, creativo y comunicativo de la persona,

- de naturaleza individual y grupal que genera interacción con el otro, los otros, y lo otro.

Todo ello nos lleva a cuestiones tan substantivas como las teorías del aprendizaje, los procesos psicológicos básicos, o las inteligencias múltiples (Mestre Navas, Palmero Cantero et al., 2004; Navarro Guzmán, Martín Bravo et al., 2010).

Considerando el juego antes propuesto vemos como el grupo y cada uno de sus integrantes pone en marcha formas de acción que implican estrategias diferentes de aprendizaje, desde la imitación a la resolución de problemas (Pérez Gómez, 1993). En un análisis más demorado, cabría considerar un modo "dramático" de aprender asentado en la experimentación desde la acción y a través del juego. En ese juego estaremos desarrollando la percepción, la atención, la memoria, el lenguaje, la emoción, la motivación, la creatividad o el pensamiento, a través de aprendizajes asentados en un modelo hipotético y deductivo, en el uso permanente del "como si", y en un procesamiento constante de toda la información que nace de la persona, del grupo y del propio juego del grupo.

Si bien Gardner en sus trabajos sobre la educación artística jamás menciona la educación teatral, cabría considerar hasta qué punto, como han sugerido Burke o Goffman (1959), no cabría hablar de una inteligencia dramática, aquella que el individuo activa en la adecuación de su conducta, de los roles que desempeña, ante cada situación de vida, con lo que genera en cada caso una "dramaturgia de la existencia". En buena medida podemos decir que si existe una expresión dramática como base de la conducta dramática, de igual modo que existiría un pensamiento "dramático" que está presente en nuestros actos más cotidianos, y que se manifiesta siempre que anticipamos conductas, prevemos situaciones o analizamos conflictos.

\section{La cuestión terminológica}

Courtney (1989) señalaba como el "educational drama" presentaba una pluralidad de opciones derivada de las diferentes fuentes que inciden en su desarrollo. En 1980 Mantovani señalaba las dificultades para "encontrar unanimidad para designar a esta actividad" pues "las palabras usadas tienen que ver con metodologías distintas, diferentes criterios, formas de trabajo y preferencias por determinados aspectos en detrimento de otros" (p. 130). Años más tarde Motos y Tejedo (1987, p. 13) insisten en la confusión terminológica, sin aportar soluciones, como lo harán Tejerina (1994, p. 121) o Núñez Cubero y Navarro Solano (2007). Con todo, la cuestión es más sencilla de lo que pudiera pensarse dado que la solución radica en no confundir disciplinas con procedimientos. Cuando hablamos de "juego dramático" o "dramatización" hacemos referencia a procedimientos propios de la expresión dramática o teatral, por lo que no cabe confundir formas de hacer con disciplinas que no son antitéticas sino que refieren prácticas educativas diferenciadas en función de objetivos diferentes (Landier y Barret, 1991, p. 8), y de una progresión que lleva de la expresión al arte (Slade, [1954] 1978).

Es por ello que proponemos diferenciar entre expresión dramática, más orientada el desarrollo de las capacidades expresivas, creativas y comunicativas de la persona, y expresión teatral, más orientada al desarrollo de su competencia artística. Siguiendo a Courtney (1980) y a las aportaciones de la psicología evolutiva que él considera, la expresión dramática sería la disciplina a desarrollar en la educación infantil y primaria y la expresión teatral la propia de la educación secundaria y el bachillerato, si bien con otros usuarios ambas se complementan, en tanto permiten transitar entre un trabajo más centrado en la persona y un trabajo más centrado en el arte (Vieites, 2012).

\section{Formación de formadores}

Tras lo que acabamos de exponer, es fácil deducir que la formación de formadores en educación teatral es compleja, y su organización debe partir de la integración curricular de la educación teatral general en las etapas educativas de la educación obligatoria y del bachillerato. Por ello la formación de especialistas para la educación formal debe organizarse desde un pacto necesario entre las facultades de educación y las escuelas superiores de arte dramático para configurar, como ya ocurre en otros países, un grado en pedagogía teatral con validez para cualquiera de las etapas señaladas. Un grado para formar profesionales de la educación teatral, que permita potenciar esa dimensión educativa de la educación teatral, sin que ello suponga menoscabo de la razón artística.

\section{Conclusiones}

Las razones para situar la educación teatral en el centro del currículum, como proponía Bolton (1984), entre muchas otras voces autorizadas, tienen una dimensión esencialmente educativa, pero todavía queda mucho por hacer no tanto para demostrar, cuanto para mostrar, esa razón educativa, que en muchos casos las madres y padres perciben cuando sus hijas e hijos asisten a una actividad extraescolar de teatro adecuadamente planificada y educativamente organizada, lejos de la pulsión exhibicionista que a veces se alimenta sin justificación alguna. Ese es el reto fundamental para el futuro inmediato, un reto para el 
que este trabajo, y otros que llegarán, son nuestra humilde aportación.

\section{Referencias}

Bajtín, M. (1989). Teoría y estética de la novela. Madrid: Taurus.

Barker. C. (1977). Theatre Games. London: Methuen.

Bolton, G. (1984). Drama as Education. London: Longman.

Bowater, I. (1985). Drama. A Study of Underachievement. En N. McCaslin (Ed.), Children and Drama (pp. 208-218). Lanham: University Press of America.

Brook, P. (2012). El espacio vacío. Madrid: Península.

Burke, K. (1945). A grammar of motives. New York: Prentice Hall.

Caillois, R. (1967). Les jeux et les hommes. Paris: Gallimard.

Cervera, J. (1982). Historia crítica del teatro infantil español. Madrid: Editora nacional.

Coburn-Staege, U. (1980). Juego y aprendizaje. Madrid: Ediciones de la Torre.

Cook, C. (1917). The Play Way. London: Heinemann.

Courtney, R. (1980). The Dramatic Curriculum. London, Ont.: Althouse Press.

Courtney, R. (1989). Play, Drama \& Thought. Toronto: Simon \& Pierre.

Curry, S. S. (1896). Imagination and the Dramatic Instinct. Boston: Expression.

Dieste, R. (1995). El alma y el espejo. Madrid: Alianza Editorial.

Dolezel, L. (1998). Heterocósmica. Ficción y mundos posibles. Madrid: Arco Libros.

Elkonin, D. B. (1980). Psicología del juego. Madrid: Visor.

Evreinoff, N. (1927). The Theatre in Life. New York: Brentano's.

Finlay-Johnson, H. (1911). The Dramatic Method of Teaching. London: Nisbet.

Fry, E. S. (1913). Educational Dramatics. New York: Moffat.

Gardner, H. (1994). Educación artística y desarrollo humano. Barcelona: Paidós.

Giner, S. (2010). Sociología. Barcelona: Península.

Goffman, E. (1959). The Presentation of Self in Everday Life. New York: Anchor Books.

Goffman, E. (1974). Frame analysis: An essay on the organization of experience. London: Harper and Row.

Grotowski, J. (1974). Hacia un teatro pobre. México: Siglo XXI.

Herts, A. M. (1911). The Children's Educational Theatre. New York: Harper.

Hodgson, J. y Richards, E. (1982). Improvisación. Madrid: Fundamentos.

Huizinga, J. (1972). Homo ludens. Madrid: Alianza.

James, W. (1890). The Principles of Psychology, vol. 2. New York: Holt.

Landier, J. C., y Barret, G. (1991). Expression dramatique théâtre. Paris: Hatier.

Luckmann, Th. (1996). Teoría de la acción humana. Barcelona: Paidós.
Mantovani, A. (1980). El teatro, un juego más. Madrid: Nuestra cultura.

Mestre Navas, J. M. y Palmero Cantero, F. (2004). Procesos Psicológicos Básicos. Madrid: McGraw Hill.

Merril, J. (1914). The value, place, and use of the dramatic instinct in the education of young people. Francis W. Parker School Year Book, 3, pp. 50-121.

Motos, T. y Tejedo, F. (1987). Prácticas de dramatización. Madrid: Humanitas.

Núñez Cubero, L. y Navarro Solano, M. R. (2007). Dramatización y educación: aspectos teóricos. Teoría de la Educación, 19, 225-252.

O'Toole, J. (1992). The Process of Drama. Negotiating Art and Meaning. London: Routledge.

Navarro Guzmán, J. I. y Martín Bravo (coords.) (2010). Psicología de la educación para docentes. Madrid: Pirámide.

Passatore, F., Destefanis, S., Fontana, A. y De Lucis, F. (1984). Yo soy el árbol, tú el caballo. Barcelona: Reforma de la Escuela.

Pérez Gómez, A. I. (1994). Los procesos de enseñanzaaprendizaje. En J. Gimeno Sacristán y A. I. Pérez Gómez, Comprender y transformar la enseñanza, pp. 34-62. Madrid: Morata.

Sarason, S. (2002). La enseñanza como arte de representación. Buenos Aires: Amorrortu.

Schechner, R. (2002). Performance Studies. An Introduction. New Yor: Routledge.

Siks, G. B. (1985). Drama in Education. A Changing Scene. En N. McCaslin (Ed.), Children and Drama (pp. 1-14). Lanham: University Press of America.

Slade. P. (1978). Expresión dramática infantil. Madrid: Santillana.

Tejerina, I. (1994). Dramatización y teatro infantil. Madrid: Siglo XXI.

Vieites, M. F. (2012). Después de la LOE. Presente y futuro de la educación teatral en España en los inicios del siglo XXI. Don Galán, 2. http://teatro.es/contenidos/donGalan/donGalanNum2/

Vieites, M. F. (2013). La construcción de la pedagogía teatral como disciplina científica. Revista Española de Pedagogía, 256, pp. 493-508.

Vieites, M. F. (2014a). Educación teatral: una propuesta de sistematización. Teoría de la educación,26 (1), pp. 77-101.

Vieites, M. F. (2014b). La educación teatral: nuevos caminos en historia de la educación. Historia de la educación, 33, pp. 325-350.

Watzlawick, P., Bavelas, J. B. y Jackson, D. D. (1991). Teoría de la comunicación humana. Barcelona: Herder.

Winkin, Y. (ed.) (1984). La nueva comunicación. Barcelona: Kairós.

Winnicott, D. W. (1971). Playing and Reality. London: Tavistock. 